\title{
Investigation of mechanical behaviour of natural composites (snake grass and elephant grass) with poly lactic acid
}

\author{
C. Thiruvasagam ${ }^{1 *}$, S. Prabagaran ${ }^{2}$, P. Suresh $^{3}$ \\ ${ }^{I}$ Research Scholar, Dept. of Mechanical Engineering, Karpagam Academy of Higher Education, Coimbatore, Tamilnadu, India \\ ${ }^{2}$ Professor, Dept. of Mechanical Engineering, Karpagam Academy of Higher Education, Coimbatore, Tamilnadu, India \\ ${ }^{3}$ Professor, Dept. of Mechanical Engineering, Muthayammal Engineering College, Rasipuram, Tamilnadu, India \\ *Corresponding author E-mail: thiruvasagam82@yahoo.co.in
}

\begin{abstract}
The Poly Lactic Acid (PLA) is a completely biodegradable potential alternate of plastics applied in Civil infrastructural field because it posses very good "Ultimate Withstanding" properties. It can also be stated that hybrid fiber composite is having higher Mechanical and Physical characteristics compared with Mono fiber reinforced composite. Naturally existing Snake Grass (SG) and Elephant Grass (EG) reinforced PLA matrix fabrication is being narrated in this research article. By experimentation and analysis of results, it is proved that the Tensile strength, \% Elongation, Flexural strength, Impact strength and Water absorption properties of SG \& EG reinforced PLA composite is better than that of pure PLA Matrix.
\end{abstract}

Keywords: Poly Lactic Acid, elephant Grass, Snake Grass, mechanical properties, flexural properties.

\section{Introduction}

The use of natural fibers as reinforcement in composites has considerably increased during recent decades. Even though there is a very large variety of fibers, matrices and manufacturing techniques used to produce natural fiber composites. Presently Fibers that are available plenty in nature are finding most applications rather than the utilities of artificial Fibers because of its bio degradability, affordable price, less light and improved Mechanical and physical properties. Inspite of high cost, few artificial fiber composites are now being applied in specific areas like aeronautical and military utilities. H.Anuar [1] stated in his article that PLA is a linear aliphatic thermo plastic polyester manufactured by the way of circular opening polymerization of Lactic Acid (LA) monomer which can be achieved from fermentation of renewable resources such as corn, sugar, beet, wheat, sugarcane or any starch-rich source material

J. P. Mofokeng, [2] examined it as being due to the incompatibility between the fibers and the matrix, which promoted micro crack formation at the interface as well as no uniform stress transfer due to fiber agglomeration in the matrix. The reports on this had indicated an increase in the thermal stability of the PLA in the presence of Fibers. Rafael A. Auras [3] gives the properties of PLA such as glass transition temperature (Tg) of PLA ranges from 50 to $80^{\circ} \mathrm{C}$ while the melting temperature $(\mathrm{Tm})$ ranges from 130 to $180^{\circ} \mathrm{C}$. K. Murali Mohan Rao, [4] had explained the extraction process of Elephant grass fiber and properties of elephant grass fiber. The tensile strength and the modulus of chemically extracted elephant grass fiber composites have increased by approximately 1.45 times to those of elephant grass fiber composite extracted by retting process. Kovier. K [5] researchers have reported the tensile properties of elephant grass fibers in literature. K. Ramanaiah [6] narrated in this article about information on thermo physical properties of natural fiber reinforced composites over and above room temperature. TP. Sathish Kumar narrated in the article [7] that the SG Fibers have been extracted by traditional water soaking process. B. Vijaya Ramnath [8] gives the details about the preparation of composites and matrix mixture ratio. Herrera-Franco and Valadez-Gonzalez [9] presented in their article that there is a vast improvement in Tensile properties in the case of small and breaking fibers rather than long and unbroken fibers. Rigoberto et al. [10] discussed in detail about the importance of natural fibers in this article. Sergio et al. [11] proposed that SG and EG natural fiber composites are being considered extensively as an alternative to the number of internal and external parts of automobile vehicles. M. Boobalan's [12] research was on the fabrication techniques of natural fiber composites at different compositions and detailed on the analysis part of Mechanical, Physical and Thermal characteristics of those composites.

VS Sreenevasan's [13] [14] work described the tensile, flexural and impact characteristics of roughly merged SGF composites. The Composites were manufactured using basic SG fibers including the differencing fiber by volume and mass $\%$. of fiber analyzed the micro structural, physic-chemical and mechanical properties of SCFs. K. Murali Mohan Rao [15] described in this article on Test procedures for finding Tensile strength, Flexural strength and then compared with composites which are made under laboratory conditions. N.Venkateshwaran [16] determined Tensile, flexural, impact and water absorption behaviors of fiber composites were carried out by optimum fiber length and weight percentage. Kasama and Nitina [17] studied the effect of glass fiber hybridization on properties of sisal fiber-polypropylene composites. Incorporation of glass fiber increases the mechanical, thermal and water resistance properties.

Recent studies in respect to mechanical behavior of reinforcement fibers in composites show that these materials can present structural and non-structural applications. The compression and 
injection molding processes were performed in order to evaluate the better mixer method for fiber and matrix. In this research article, the complete process fabrication of composites and PLA matrix reinforced with SG and EG at different volume fractions by water soaking process. With these specimens, experimentations have been conducted to check Tensile strength, Flexural strength, $\%$ elongation, Impact strength and Water absorption properties.

\section{Materials}

\subsection{Natural fibers}

A natural fiber is a nature bound in fibrous materials, especially cellulosic types such as cotton, wood, grains, and straw used for textile products or other industrial purposes. Apart from the economic considerations, the usefulness of a fiber for commercial purposes is determined by such properties as length, strength, pliability, elasticity, abrasion resistance, absorbency, and various surface properties. There are two major groups of natural fibers which are in present use. They are fibers from animals and fibers from vegetation plants. Usually vegetation plants are cheaper and easily available for reach.

\subsubsection{Elephant grass fiber}

Elephant grass (Botonical term: Pennisetum purpureum) is nothing but a long grass. Origin of this plant was Africa in the early $20^{\text {th }}$ century. It was cultivated along the river bed and Lake slides and grow upto $300 \mathrm{cms}$ long. Colour is pale yellow. Stem at the base is having $2.5 \mathrm{cms}$ diameter and leaves are as long as 100 . The extracted elephant grass fiber is shown in fig. 1(a). Although the elephant grass is renewable and it is available abundantly in the nature, its potential and economical source could be compared to other fibers which are still underutilized. The physical and Mechanical Properties of Elephant grass fiber is shown in Table 1.

\subsubsection{Snake grass fiber}

In south zone of our country, Snake Grass fiber is recently introduced fiber which is extracted by water soaking technique. The Properties of Snake grass fiber is shown in Table 1. For achieving improved mechanical and physical properties, the technical parameters that influences being the lignin, pectin and angle of micro fiber. The extracted elephant grass fiber is shown in fig. 1(b). In this, micro fibril angle of SG is lower in comparison with other fiber. Adhesiveness property of fiber is depending on the Lignin availability in the fibers.

Table 1: Properties of Elephant Grass and Snake Grass Fibers

\begin{tabular}{|c|c|c|c|c|}
\hline Fibers & $\begin{array}{l}\text { Density } \\
\left(\mathrm{kg} / \mathrm{m}^{3}\right)\end{array}$ & $\begin{array}{c}\text { Tensile Strength } \\
(\mathrm{MPa})\end{array}$ & $\begin{array}{c}\text { Tensile Modulus } \\
(\mathrm{GPa})\end{array}$ & $\begin{array}{c}\text { Elongation } \\
\% \\
\end{array}$ \\
\hline Snake Grass & 887 & $287-545$ & 9.7 & 2.87 \\
\hline Elephant Grass & 817.53 & $185-327$ & 7.4 & 3.23 \\
\hline
\end{tabular}

Table 2: Mechanical Properties of Poly Lactic Acid (PLA)

\begin{tabular}{ccccccc}
\hline Material & $\begin{array}{c}\text { Density } \\
\left(\mathrm{g} / \mathrm{cm}^{3}\right)\end{array}$ & $\begin{array}{c}\text { Tensile Strength } \\
(\mathrm{MPa})\end{array}$ & $\begin{array}{c}\text { Tensile Modulus } \\
(\mathrm{GPa})\end{array}$ & $\begin{array}{c}\text { Elongation } \\
\%\end{array}$ & Melting Point $\left({ }^{\circ} \mathrm{C}\right)$ & Glass Trans. Temp $\left({ }^{\circ} \mathrm{C}\right)$ \\
\hline PLA & 1.9 & 50 & 3.5 & 6 & 60 \\
\hline
\end{tabular}

\subsection{Poly lactic acid (PLA)}

PLA is a biodegradable and bioactive thermoplastic aliphatic polyester derived from renewable resources, such as corn starch (in United States and Canada), tapioca roots, chips or starch (mostly in Asia), or sugarcane (in the rest of the world). In 2010, the PLA was the second highest consumption volume of any bio plastic of the world. The properties of PLA are given in Table 2 . The name "polylactic acid" does not comply with IUPAC standard nomenclature, and is potentially ambiguous or confusing, because PLA is not a polyacid (polyelectrolyte), but rather polyester. The pelletized PLA is shown in Fig. 1(c).

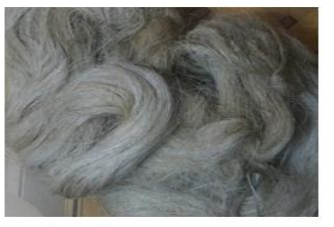

a) Extracted elephant grass fiber

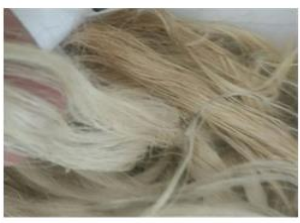

b) Extracted snake grass fiber

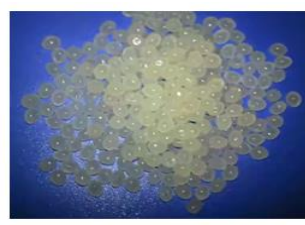

c) PLA

Fig. 1: Materials

composite underwent injection moulding process at $185^{\circ} \mathrm{C}$. In this process the test specimens are prepared in the size of $25 \times 2.5 \mathrm{x}$ $0.3 \mathrm{cms}$ for conducting Tensile, Flexural, Impact and Water absorption experimentations.

Table 3: The Formulation of Composites Prepared

Elephant Grass are being manufactured by Natural Fiber Industries in Salem. Length and diameter are the critical parameters of Fiber. Fibers were cut by the $3 \mathrm{~mm}$ average length for preparing composites. The PLA and the SG/ EG fibers were kept in a furnace at $120^{\circ} \mathrm{C}$ for about 300 minutes before put in use. Composition of PLA and Fiber are given in Table 3. With the help of the machine Brabender Plasti-Corder type 814402, Poly Lactic Acid, Snake Grass and Elephant Grass fibers were fabricated by Extrusion process just after doing conventional mixing at $185^{\circ} \mathrm{C}$. Then this rounded compacted composite was put in the process of recrystallisation at $120^{\circ} \mathrm{C}$ for 30 minutes. Afterwards this

\begin{tabular}{|c|c|c|}
\hline Composition & PLA & Fiber \\
\hline 1 & 90 & 10 \\
\hline 2 & 85 & 15 \\
\hline 3 & 80 & 20 \\
\hline 4 & 75 & 25 \\
\hline 5 & 70 & 30 \\
\hline 6 & 100 & - \\
\hline
\end{tabular}




\section{Experimentations and analysis}

\section{4a. Experimentation for finding strength on Tension test}

The Test specimens are prepared as per the standard ASTM D3039 corresponding to different compositions as prescribed in Table 3. Series of tests have been conducted to find Tensile strength, \% Elongation and Breaking point. The size of specimen is machined a standard size of $25 \times 2.5 \times 0.3 \mathrm{~cm}$. The schematic diagram of tensile test specimen is shown in fig. 2(a). The tests were carried out using a kalpak universal testing machine. It has the specification of KIC 2-1000-C maximum capacity $100 \mathrm{KN}$. Required test samples are manufactured based on SG and EG fiber composite. The findings have been consolidated based on the 6 similar experimentation samples.

\section{4b. Experimentation for finding flexural strength}

The Test specimens of $12.5 \times 1.3 \times 0.3 \mathrm{~cm}$ have been prepared as per the standard ASTM D790 which are shown in figure $2 \mathrm{~b}$ and a) Tensile test

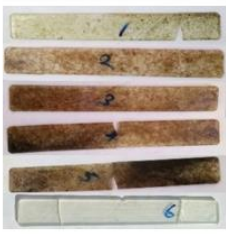

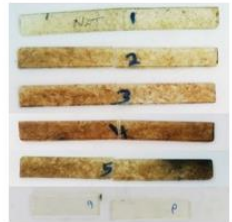

b) Flexural test

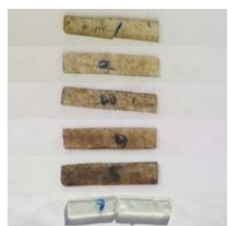

c) Impact test

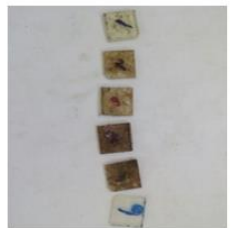

d) Water absorption test
Fig. 2: Tested Specimens

characteristics. It is clearly shown in figure 3 that the Stress is increasing when the Strain is increased upto the PLA with 25\% reinforcement. Afterwards it starts reducing.

Similarly from the figure $4 \mathrm{a}$, it is evident that Tensile strength increases steadily for the increase in vf up to $25 \%$. Then it starts reducing further when comparing with the pure PLA matrix.

Also from the figure $4 \mathrm{~b}$, it is evident that Elongation increases steadily for the increase in addition of vf up to $25 \%$. Then it starts reducing further when comparing with the pure PLA matrix for calculating the stress and strain with respect from PLA upto PLA with $30 \%$ vf. These values had been used to plot the the series of tests to different compositions as prescribed in Table 3 have been conducted in the same universal Testing Machine and Bending modulus.

The Test specimens of $6.5 \times 1.3 \times 0.3 \mathrm{~cm}$ have been prepared as the series of tests to different compositions as prescribed in Table 3 have been conducted in the Impact Testing Machine with IZOD me readings have been recorded for further analysis. Experimentation for finding Water absorption strength: composite specimen immersed in water at 48 hours in room as per freshly cut samples of dimension $20 \mathrm{~mm} x$ $20 \mathrm{~mm} \times 3 \mathrm{~mm}$ used for measure of water absorption. The tested specimens are shown in fig. 2(d). graph which is depicted in figure 3 . From the trend of the curve it goes, it resembles the behavior of brittle nature with elastic

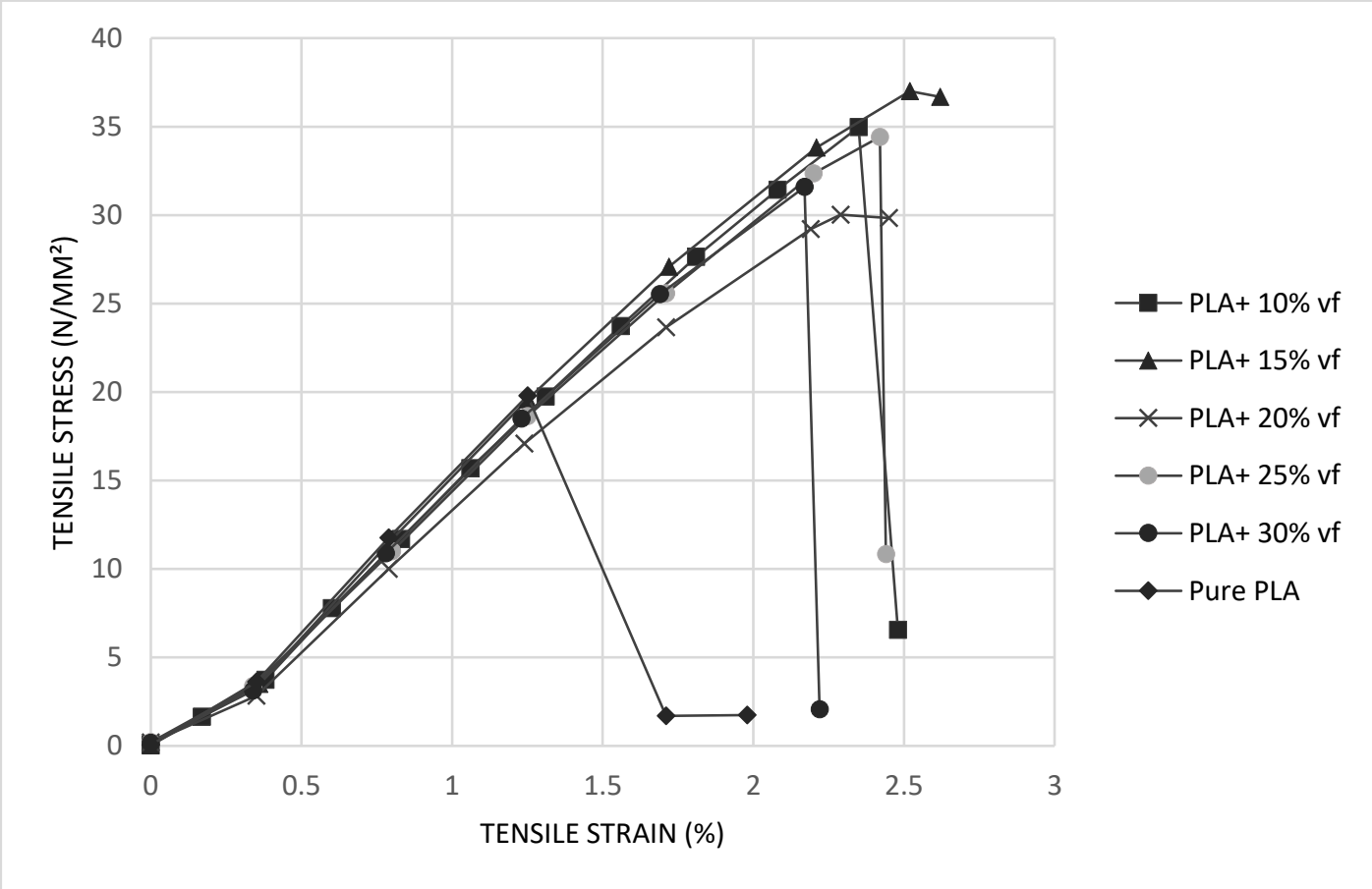

Fig. 3: Stress-strain behavior of PLA composites at different fiber weight percent's 


\section{Tensile Strength of the Composite}

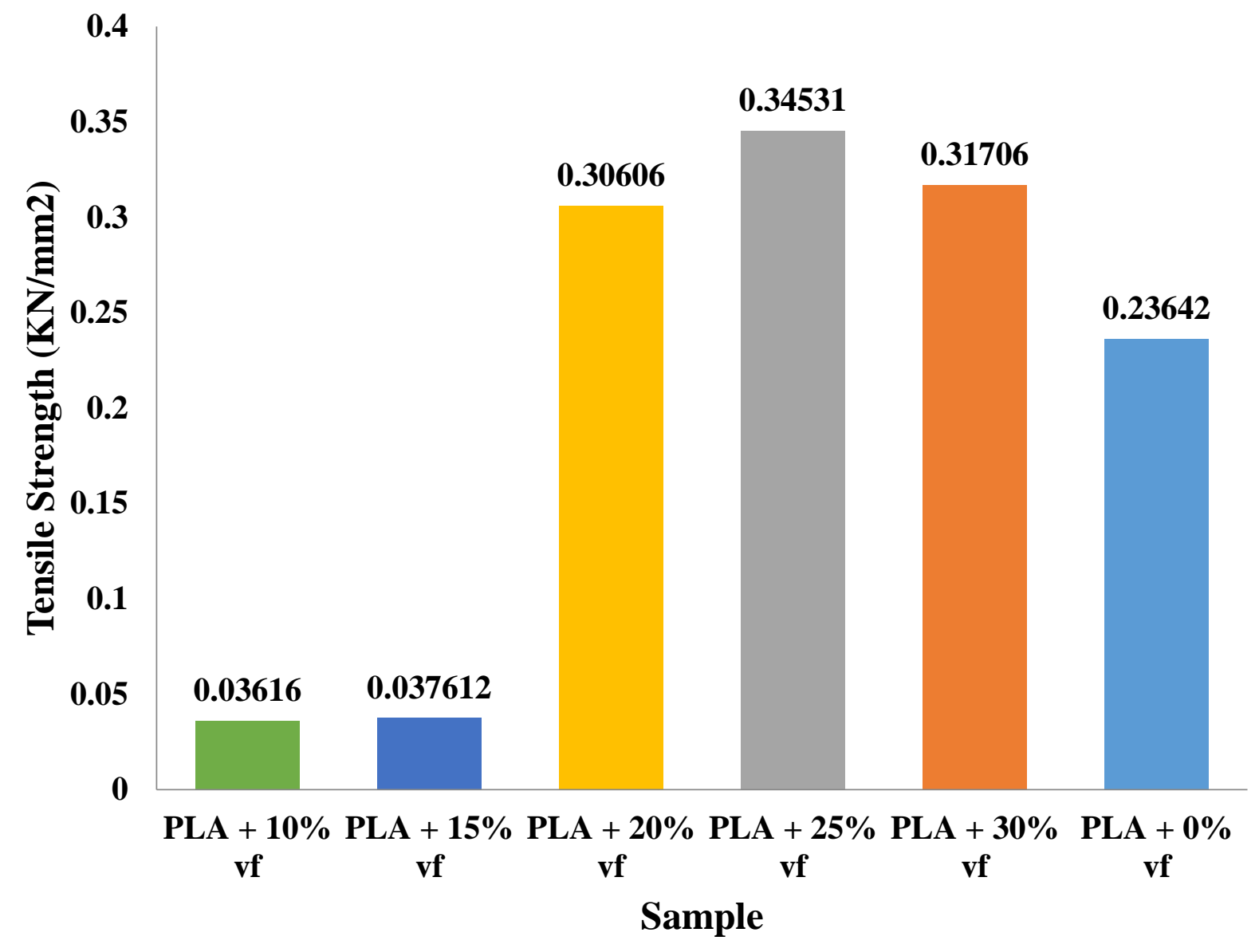

Fig. 4a: Comparison of Tensile strength for various fiber weight compositions of PLA composites

\section{Elongation of the Composite}

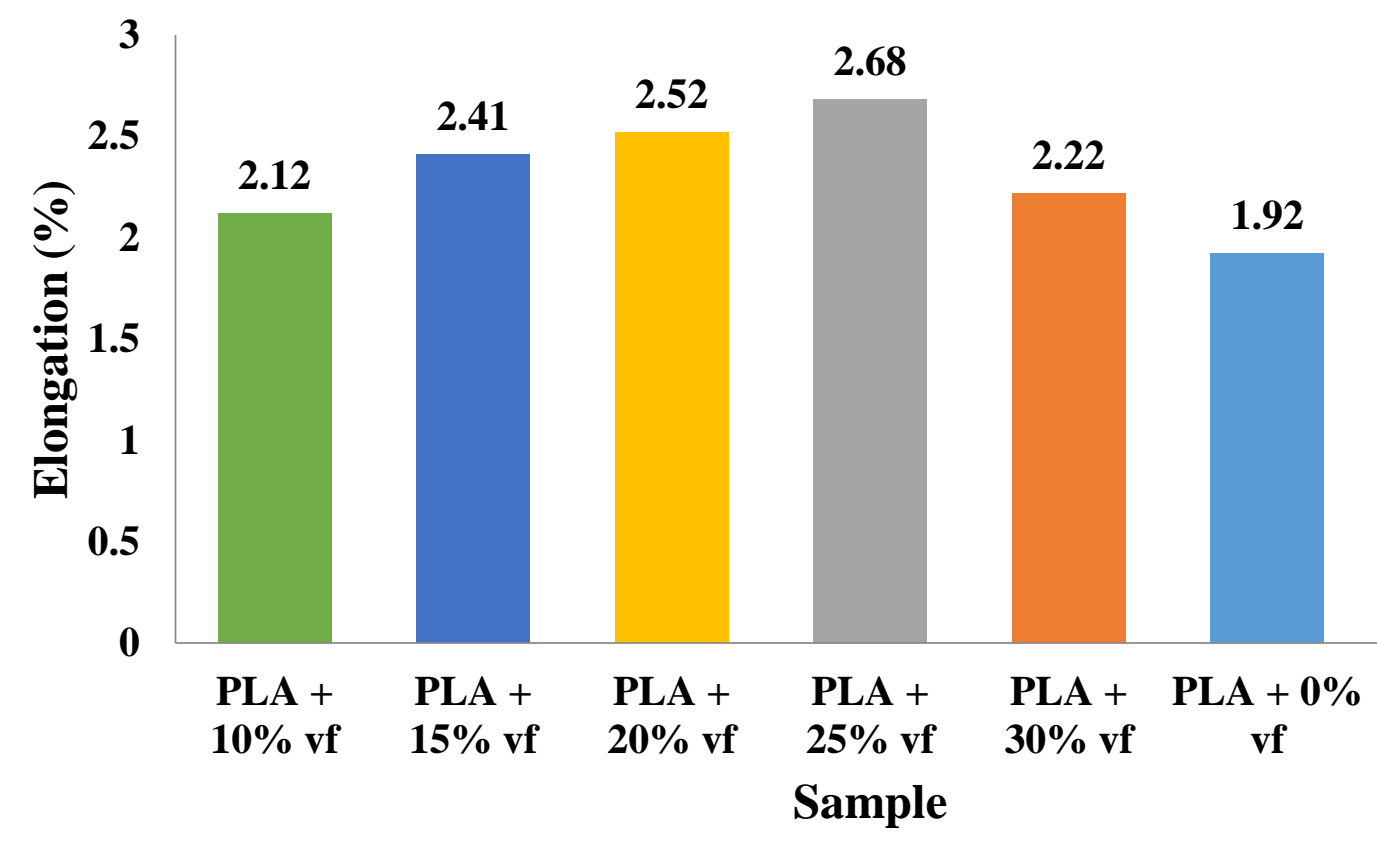

Fig. 4b: Comparison of Elongation for various fiber weight compositions of PLA composites 


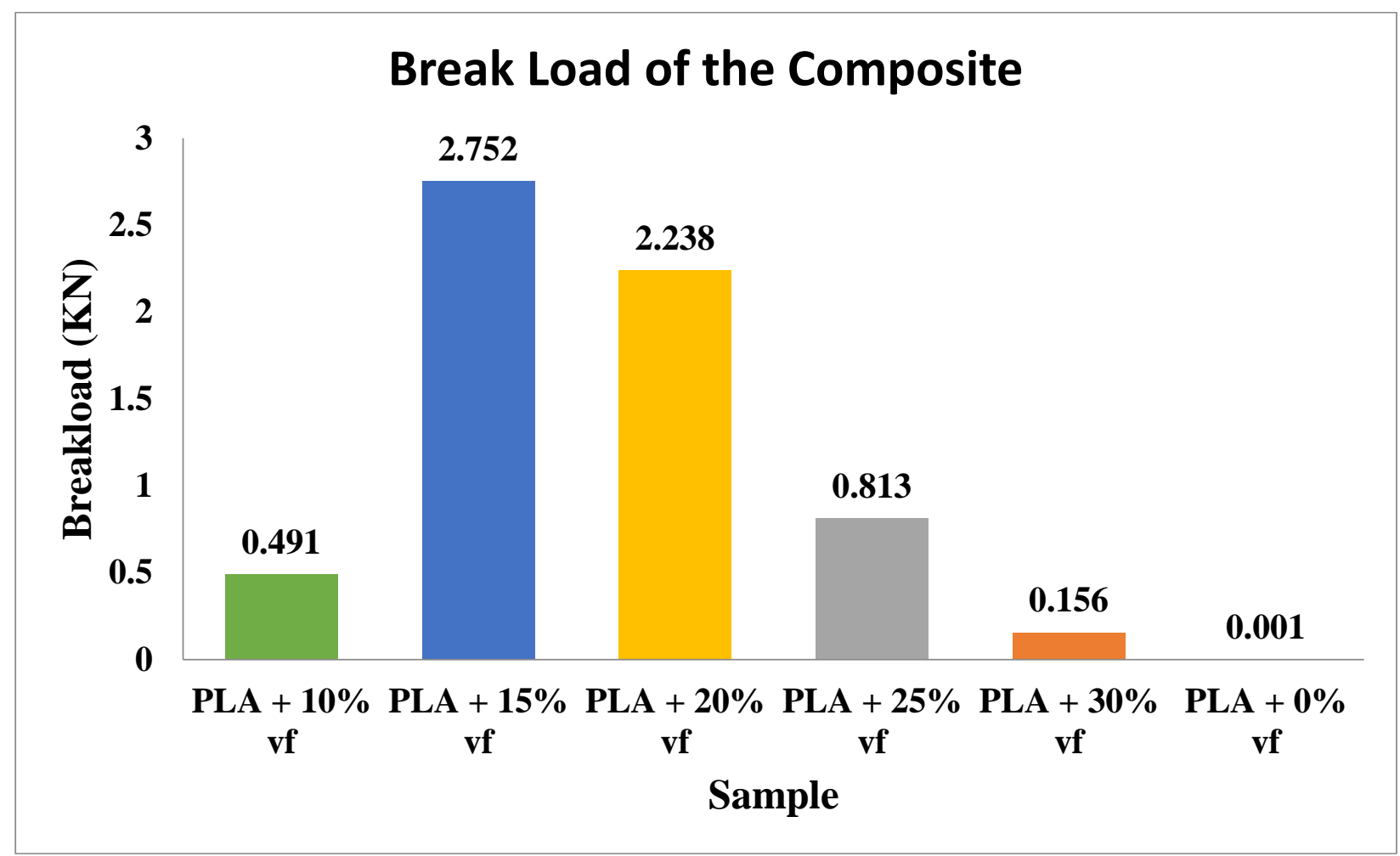

Fig. 4c: Comparison of Break load for various fiber weight compositions of PLA composites

Figure $4 \mathrm{c}$ depicts the pattern of Break load with respect to the composition of each PLA and \% of vf. It describes that the break loads get highest value in the $15 \%$ of vf and then decreases up to $30 \%$ of vf. The pure PLA has the lowest value of break load.

\subsection{Flexural Properties}

The influence of reinforcement - Fiber addition on PLA matrix are being seen from the figure 5 which was plotted in a linear graph based on the readings obtained from the Flexural experimentations. From the figure it is evident that the Flexural strength increasing steadily when the \% of vf with PLA matrix is increased from $10 \%$ upto $20 \%$ and then there is drop at $25 \%$ addition which is further taken forward. But maximum strength is obtained at the addition of $20 \%$ vf. In order to make the discussion strong, with the same readings, Column chart is also plotted for this Flexural strength which is shown as figure 6a. Here also it is clearly understood that, Flexural strength increasing steadily for the addition of fiber with PLA matrix upto $20 \%$ and then there is drop at $25 \%$ vf which is further taken forward. Again the statement can be reinstated that maximum Flexural strength is obtained at the addition of $20 \% \mathrm{vf}$.

The effect of Modulus of Bending can be seen from the figure $6 \mathrm{~b}$ which is plotted from the readings obtained from the experimentations. Bending modulus is increasing when the addition of fibers vf upto $20 \%$ with the PLA matrix. Afterwards there is slash in Bending modulus at $25 \%$ addition which is then getting raised upto $30 \%$ but slightly lesser than that of Bending modulus obtained at $20 \%$ addition. Hence it is observed that the maximum Bending modulus is obtained at $20 \%$ addition of fibers with PLA matrix.

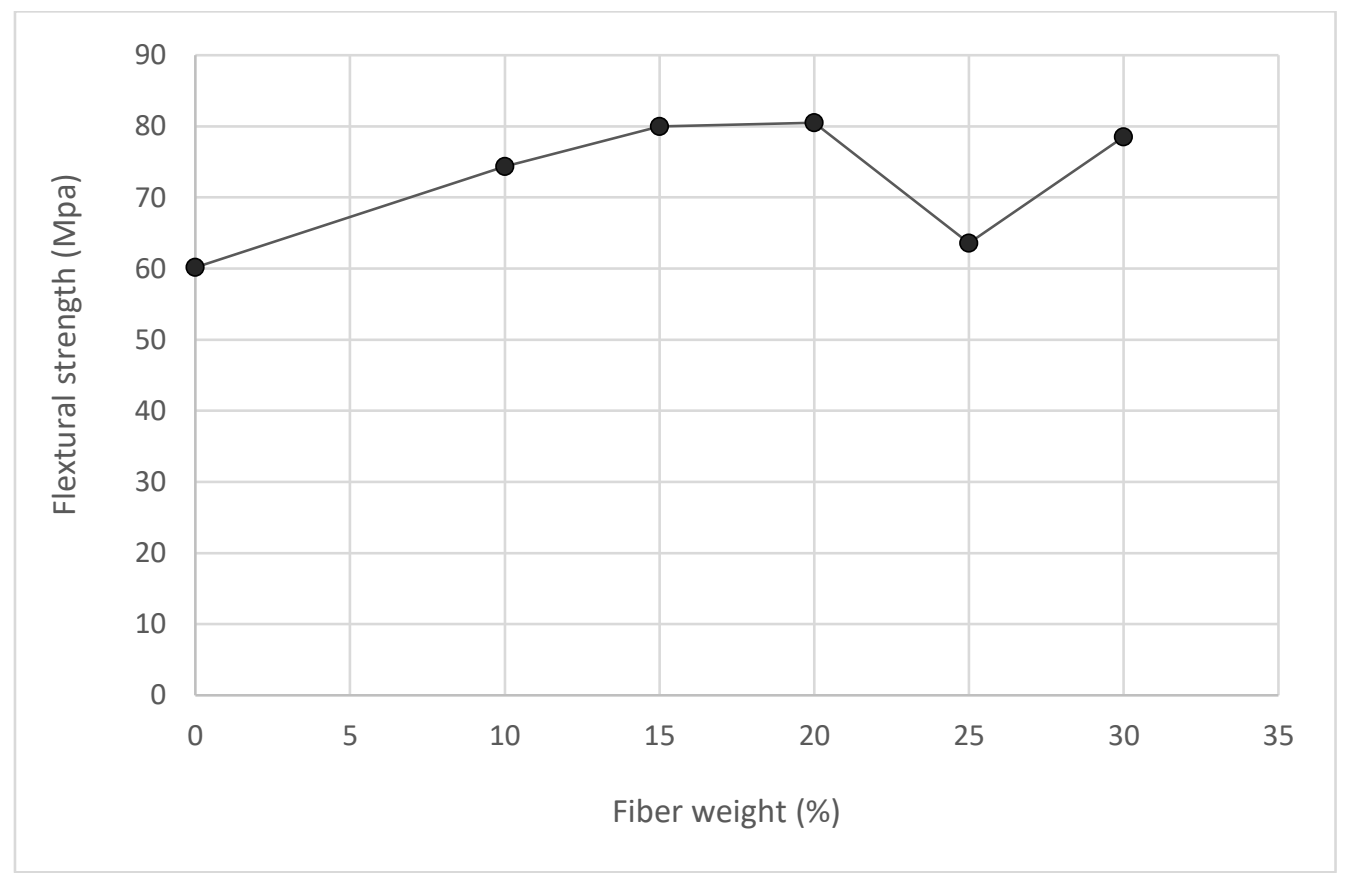

Fig. 5: Variation of flexural strength with various fiber weight percent of PLA composites 


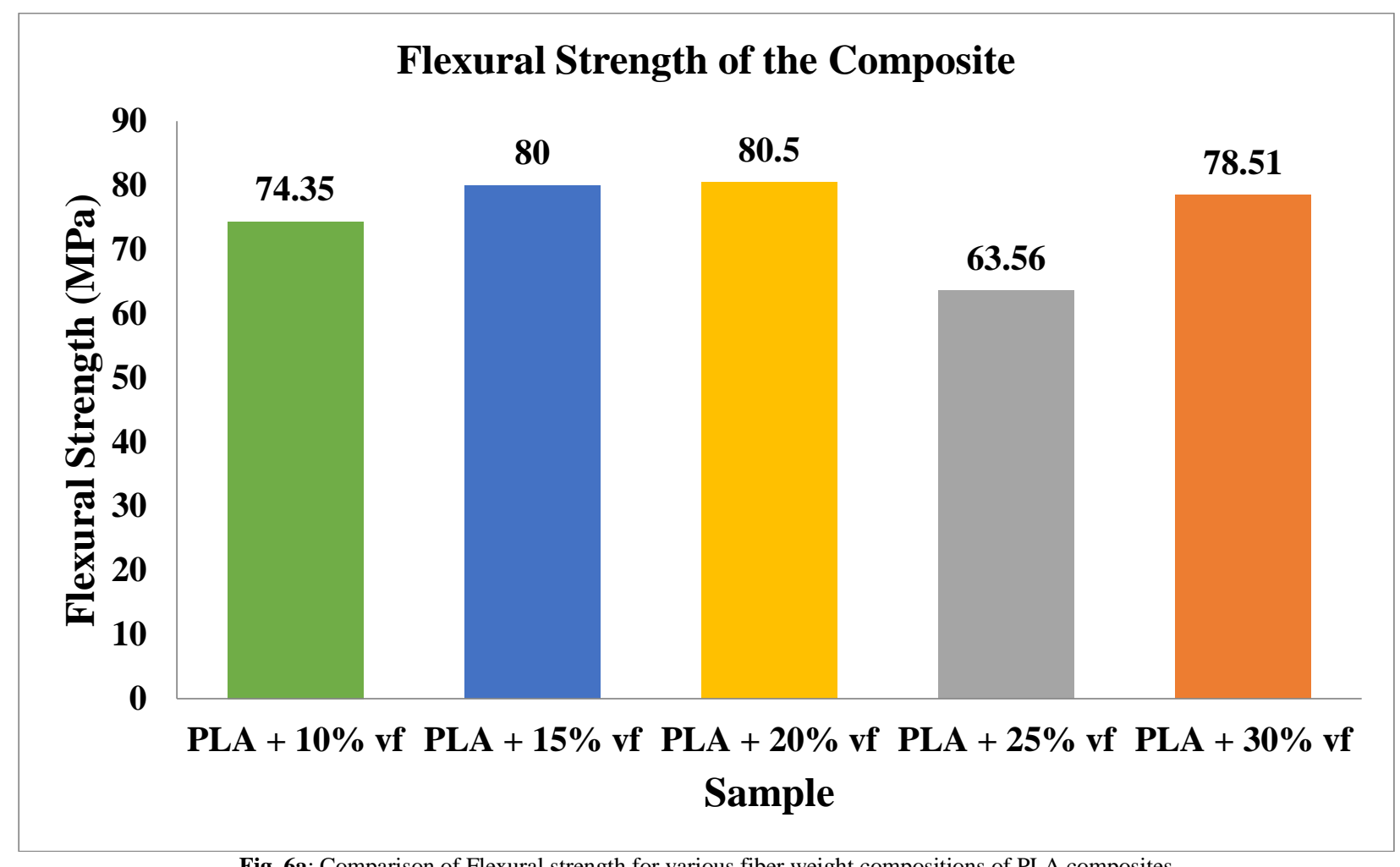

Fig. 6a: Comparison of Flexural strength for various fiber weight compositions of PLA composites

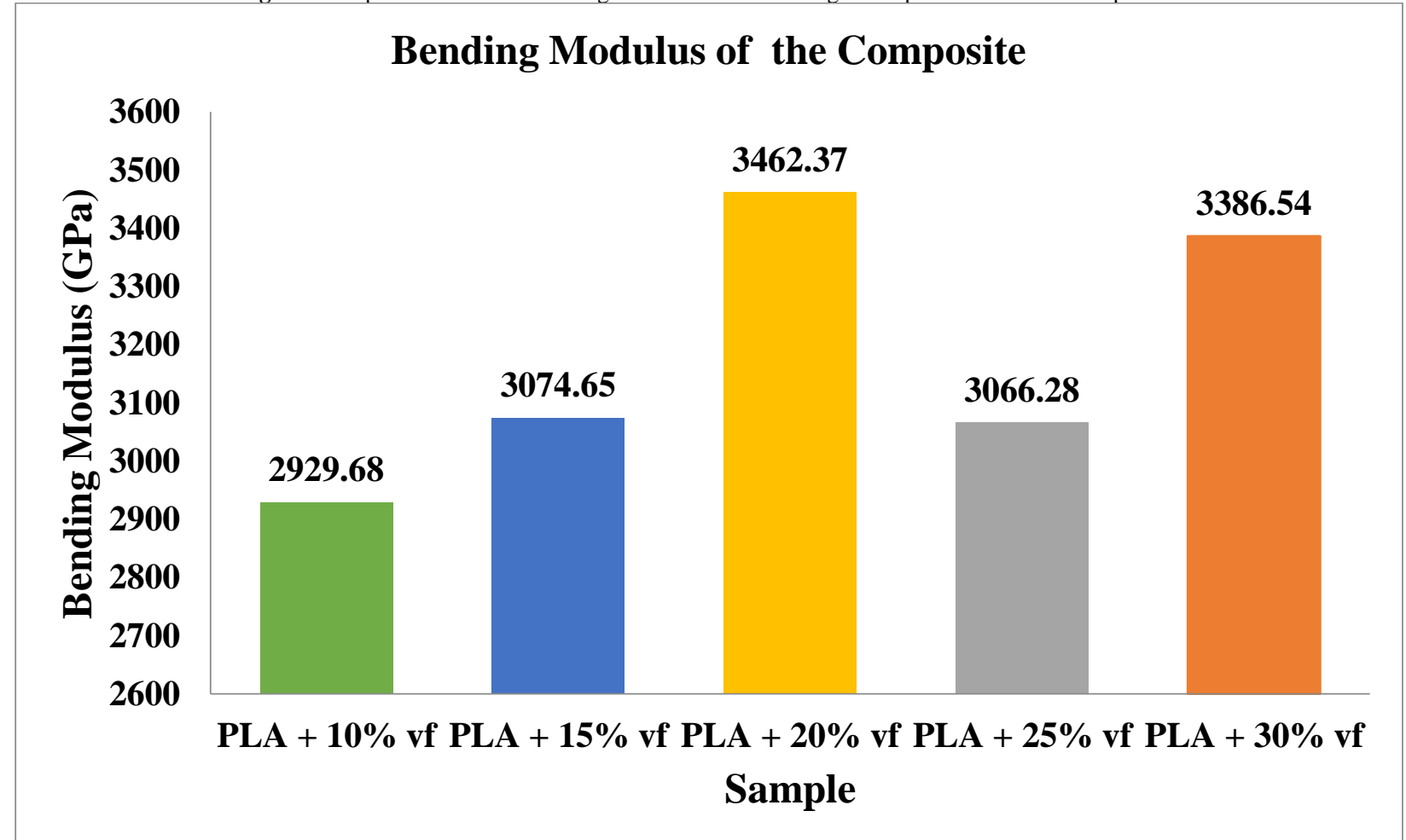

Fig. 6b: Comparison of Bending Modulus for various fiber weight compositions of PLA composites

\subsection{Impact properties}

For a specific fiber length, the impact strengths which are obtained for various fiber weight $\%$ have been plotted in a graph and the same is shown in figure 7 . The impact strength is getting decreased in comparison with pure PLA matrix upto $10 \%$ vf Afterwards upto $30 \%$ of vf reinforcement, the impact strength is steadily increasing and goes to the maximum value of 0.55 joules whereas the impact strength of pure PLA matrix being 0.46 joules. 


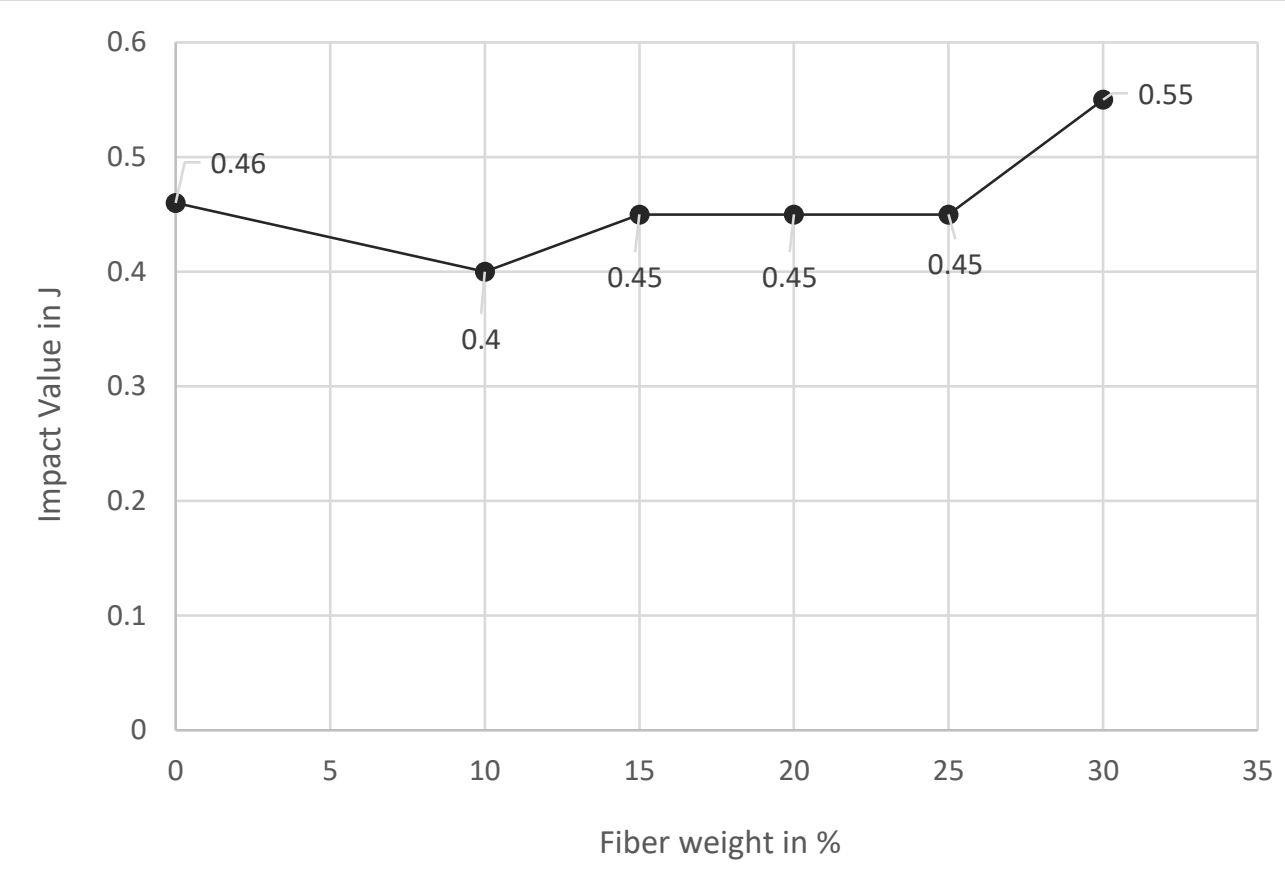

Fig. 7: Variation of impact strength with fiber weight percent for PLA composites

\subsection{Water absorption properties}

6

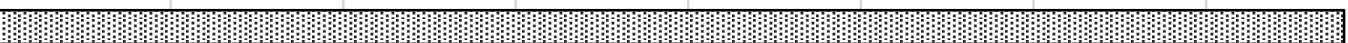

级

5

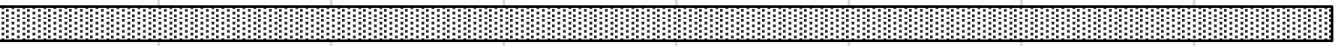

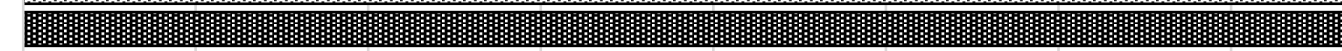

4

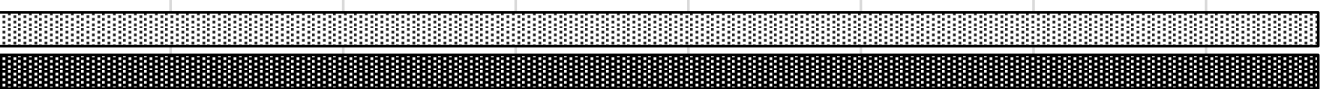

3

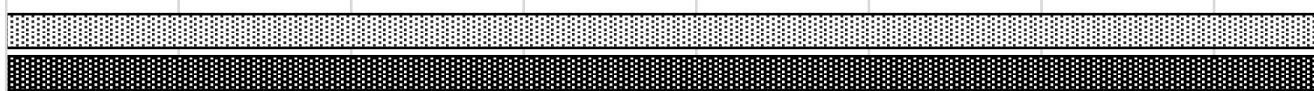

$\mathbb{Z}$

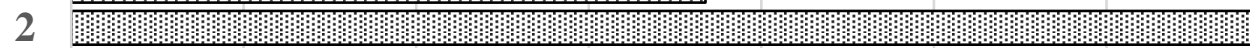

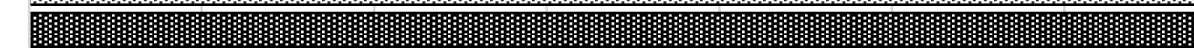

1
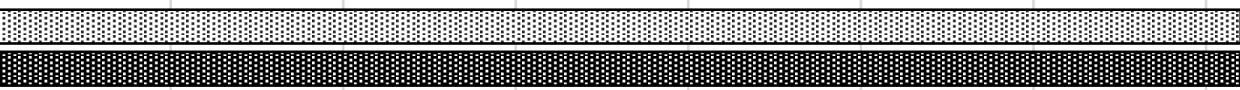

0

0.2

0.4

0.6

0.8

1

1.2

1.4

1.6

1.8

$\square \%$ of Water absorption

图 Weight after test in gms (48 hrs )

\section{国 Weight before test in gms}

Fig. 8: Comparison of water absorption properties of fiber composites

The water absorption behavior of all five specimens was immersed in water at $23^{\circ} \mathrm{C}$ as per ASTM D 570. The increase in determined in terms of weight increase for composite specimen weight percent were compared in the Fig. 8. 


\section{Scanning electron microscope (SEM) analysis}

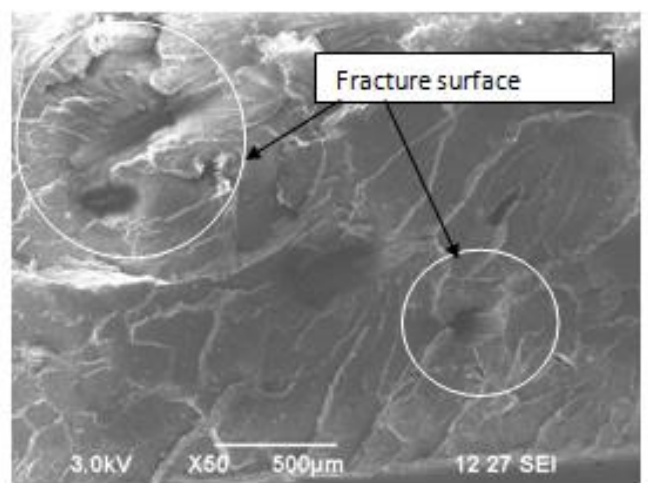

(a) Composite imaging upon tensile experimentation

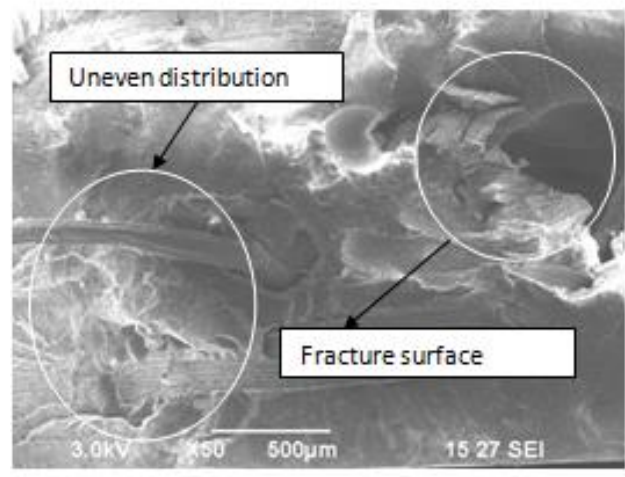

(c) Composite imaging upon flexural experimentation

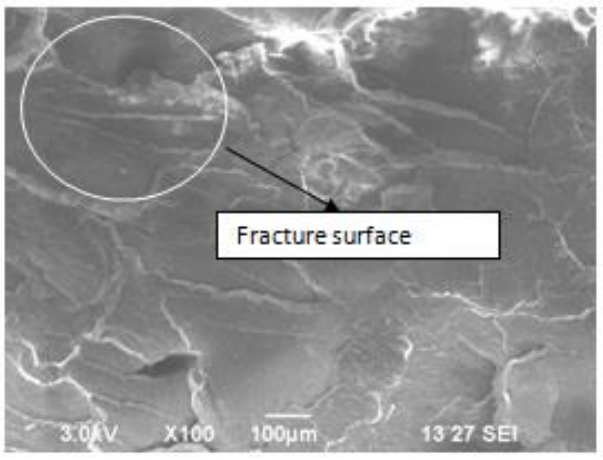

(b) Composite imaging upon impact experimentation

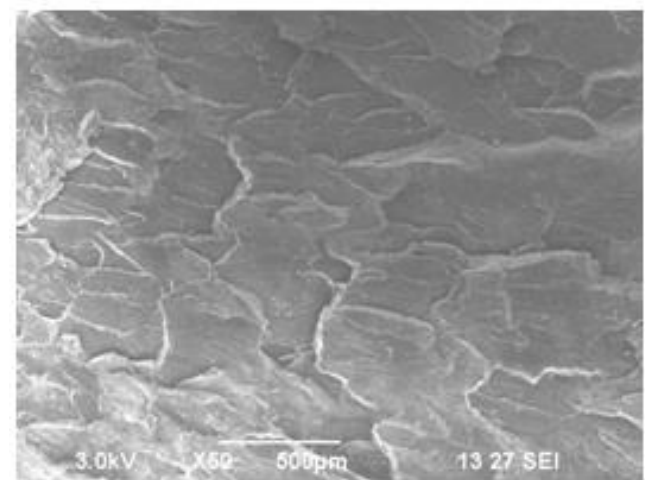

(d) PLA imaging upon tensile experimentation

Fig. 9: Scanning electron microscope (SEM) analysis

By means of SEM, the cross sectional surface texture of SG,EG,PLA composite was being analysed and the same is depicted in figure 9.

Before doing SEM analysis, the composite specimens were being given with conducting material lining. Purpose of SEM analysis is to observe the fractured surface structure and any defects like crack, blow holes etc.

Figure 9a depicts the images after doing tensile test of composite material. Figure $9 \mathrm{~b}$ depicts the images after doing Impact test of composite material where the material is getting disintegrated at breaking point is being observed. Figure $9 \mathrm{c}$ depicts the images of composite after doing Flexural test. Figure 9d depicts the images of PLA after doing tensile test.

\section{Conclusion}

The Bio composite was manufactured with Poly Lactic Acid with the reinforcement of Snake Grass, Elephant Grass fibers. It was also proved that for Poly Lactic Acid with the fibers reinforcements have improved the physical, Mechanical properties and Water absorption properties in comparison with that of matrix material.

- Tensile experimentation outcome reveals that @ 25\% vf, SG and EG composites showed maximum Tensile strength of $345.31 \mathrm{~N} / \mathrm{mm}^{2}$

- Flexural experimentation outcome reveals that @ 20\% vf, SG and EG composites showed maximum Flexural strength of $80.5 \mathrm{MPa}$ and Flexural modulus of 3462.37 GPa@20\%.

- Impact experimentation outcome reveals that @ 30\% vf, SG and EG composites showed maximum Impact strength of $0.55 \mathrm{~J}$

- Tensile experimentation outcome reveals that @ 25\% vf, SG and EG composites showed maximum \% elongation of 2.68
- From these experiments it was well established that there were good interaction between Snake Grass , Elephant Grass and Poly Lactic Acid matrix.

\section{References}

[1] Anuar H, Zuraida A, Kovacs JG \& Tabi T, "Improvement of mechanical properties of injection moulded polylactic acid-kenaf fiber bio composites", Thermoplastic composite material, (2012).

[2] Mofokeng JP, Luyt AS, Tabi T \& Kovacs J, "Comparison of injection moulded, natural fiber reinforced composites with PP and PLA as matrices", Thermoplastic composite material, Vol.25, (2011), pp.927-948.

[3] Auras RA, Harte B, Selke S \& Hernandez R, "Mechanical, physical and barrier properties of polylatic film", Plastic film sheeting, Vol.02, (2003)

[4] Murali Mohan Rao K, Ratna Prasad AV, Ranga Babu MNV, Mohan Rao K \& Gupta AVSSKS, "Tensile properties of elephan grass fiber reinforced polyester composites", Material Science, Vol.42, (2007), pp.3266-3272.

[5] Kovier K, "Fiber reinforced concrete", The cement andconcrete Institute, (2001)

[6] Ramanaiah K, RatnaPrasad AV \& HemaChandraReddy K, "Thermo physical properties of elephant grass fiber-reinforced polyester composites", Materials and design, Vol.89, (2012), pp. 156-158.

[7] Sathishkumar TP, Navaneethakrishnan P \& Shankar S, "Tensile and flexural properties of snake grass natural fiber reinforcedisophthallic polyester composites", Composite Materials and Tech, Vol.72,(2012), pp.1183-1190.

[8] Vijaya Ramnath B, Junaid Kokan S, Niranjan Raja R, Sathyanarayanan R, Elanchezhian C, Rajendra Prasad A \& Manickavasagam VM, "Evaluation of mechanical properties of abaca-jute-glass fibre reinforced epoxy composite", Materials and Design, Vol.51,(2013), pp.357-366.

[9] Herrera Franco PJ \& Valadez Gonzalez A, "A study of mechanical properties of short natural fiber reinforced composites", Composites: Part B, Vol.36, (2005), pp.597-608. 
[10] Burgueno R, Quagliata MJ, Mehta GM, Mohanty AK, Misra M \& Drzal LT, "Sustainable cellular biocomposites from natural fibers and unsaturated polyester resin for housing panel applications", Journal of Polymers and the Environment, Vol.13, No.2, (2005), pp.139-149.

[11] Monteiro SN, Lopes FPD, Ferreira AS \& Nascimento DCO, "Natural-fiber polymer-matrix composites: cheaper, tougher, and environmentally friendly", JOM Journal of the Minerals, Metals and Materials Society, Vol.61, No.1, (2009), pp.17-22.

[12] Boopalan M, Niranjanaa M \& Umapathy MJ, "Study on the mechanical properties and thermal properties of jute and banana fiber reinforced epoxy hybrid composites", Composites: Part B, Vol.51, (2013), pp.54-57.

[13] Sreenivasan VS, Somasundaram S, Ravindran D, Manikandan V \& Narayanasamy R, "Microstructural, physico-chemical and mechanical characterisation of Sansevieria cylindrica fibres-an exploratory investigation", Materials and Design, Vol.32, (2011), pp.453-461.

[14] Sreenivasan VS, Ravindran D, Manikandan V \& Narayanasamy R, "Mechanical properties of randomly oriented short Sansevieria cylindrical fibre/polyester composites", Materials and Design, Vol.32, (2011), pp.2444-2455.

[15] Murali Mohan Rao K, Mohana Rao K \& Ratna Prasad AV, "Fabrication and testing of natural fiber composites: Vakka, sisal, bamboo and banana", Materials and Design, Vol.31, (2010), pp.508-513.

[16] Venkateshwaran N, ElayaPerumal A, Alavudeen A \& Thiruchitrambalam M, "Mechanical and water absorption behaviour of banana/sisal reinforced hybrid composites", Materials and Design, Vol.32, (2011), pp.4017-4021.

[17] Surendar, A., M. Kavitha, and V. Saravanakumar. "Proactive model based testing and evaluation for component-based systems." International Journal of Engineering \& Technology 8.1.1 (2018): 74-77. 